\title{
MECP2 Coding Sequence and 3'UTR Variation in 172 Unrelated Autistic Patients
}

\author{
Ana M. Coutinho, ${ }^{1}$ Guiomar Oliveira, ${ }^{2}$ Cécile Katz, ${ }^{3}$ Jinong Feng, ${ }^{3}$ Jin Yan, ${ }^{3}$ Chunmei Yang, ${ }^{3}$ \\ Carla Marques, ${ }^{2}$ Assunção Ataíde, ${ }^{4}$ Teresa S. Miguel, ${ }^{4}$ Luís Borges, ${ }^{2}$ Joana Almeida, ${ }^{2}$ Catarina Correia, ${ }^{1,9}$ \\ António Currais, ${ }^{1}$ Celeste Bento, ${ }^{2}$ Luísa Mota-Vieira, ${ }^{5}$ Teresa Temudo, ${ }^{6}$ Mónica Santos, ${ }^{7,8}$ Patrícia Maciel, ${ }^{7}$ \\ Steve S. Sommer, ${ }^{3}$ and Astrid M. Vicente ${ }^{1,9 *}$ \\ ${ }^{1}$ Instituto Gulbenkian de Ciência, Oeiras, Portugal \\ ${ }^{2}$ Hospital Pediátrico de Coimbra, Coimbra, Portugal \\ ${ }^{3}$ Department of Molecular Genetics, City of Hope National Medical Centre and Beckman Research Institute, Duarte, California \\ ${ }^{4}$ Direcção Regional de Educação da Região Centro, Coimbra, Portugal \\ ${ }^{5}$ Unidade de Genética e Patologia Moleculares, Hospital do Divino Espírito Santo, Ponta Delgada, Açores, Portugal \\ ${ }^{6}$ Hospital de Sto. António, Porto, Portugal \\ ${ }^{7}$ ICVS / Escola de Ciências da Saúde, Universidade do Minho, Braga, Portugal \\ ${ }^{8}$ ICBAS, Universidade do Porto, Porto, Portugal \\ ${ }^{9}$ Instituto Nacional de Saúde Dr. Ricardo Jorge, Lisboa, Portugal
}

Mutations in the coding sequence of the methylCpG-binding protein 2 gene (MECP2), which cause Rett syndrome (RTT), have been found in male and female autistic subjects without, however, a causal relation having unequivocally been established. In this study, the $M E C P 2$ gene was scanned in a Portuguese autistic population, hypothesizing that the phenotypic spectrum of mutations extends beyond the traditional diagnosis of RTT and $X$-linked mental retardation, leading to a nonlethal phenotype in male autistic patients. The coding region, exon-intron boundaries, and the whole $3^{\prime}$ UTR were scanned in 172 patients and 143 controls, by Detection of Virtually All MutationsSSCP (DOVAM-S). Exon 1 was sequenced in 103 patients. We report 15 novel variants, not found in controls: one missense, two intronic, and 12 in the $3^{\prime}$ UTR (seven in conserved nucleotides). The novel missense change, c.617G $>C$ (p.G206A), was present in one autistic male with severe mental retardation and absence of language, and segregates in his maternal family. This change is located in a highly conserved residue within a region involved in an alternative transcriptional repression pathway, and likely alters the secondary structure of the MeCP2 protein. It is therefore plausible that it leads to a functional modification of MeCP2. MECP2 mRNA levels measured in four patients with $3^{\prime}$ UTR conserved changes were below the control range, suggesting

This article contains supplementary material, which may be viewed at the American Journal of Medical Genetics website at http://www.interscience.wiley.com/jpages/1552-4841/suppmat/ index.html.

Grant sponsor: Fundação Calouste Gulbenkian (FCG); Grant sponsor: Fundação para a Ciência e a Tecnologia (FCT); Grant number: POCTI/39636/ESP/2001.

*Correspondence to: Astrid M. Vicente, Ph.D., Instituto Nacional de Saúde Dr. Ricardo Jorge, Av. Padre Cruz, 1649-016 Lisboa, Portugal, and Instituto Gulbenkian de Ciência, Ap. 14, 2781-901, Oeiras, Portugal. E-mail: avicente@igc.gulbenkian.pt

Received 24 June 2006; Accepted 12 December 2006

DOI 10.1002/ajmg.b.30490 an alteration in the stability of the transcripts. Our results suggest that $M E C P 2$ can play a role in autism etiology, although very rarely, supporting the notion that $M E C P 2$ mutations underlie several neurodevelopmental disorders.

(c) 2007 Wiley-Liss, Inc.

KEY WORDS: autism; MECP2; 3'UTR; exon 1; Detection of Virtually All Mutations-SSCP

Please cite this article as follows: Coutinho AM, Oliveira G, Katz C, Feng J, Yan J, Yang C, Marques C, Ataíde A, Miguel TS, Borges L, Almeida J, Correia C, Currais A, Bento C, Mota-Vieira L, Temudo T, Santos M, Maciel P, Sommer SS, Vicente AM. 2007. MECP2 Coding Sequence and $3^{\prime}$ UTR Variation in 172 Unrelated Autistic Patients. Am J Med Genet Part B 144B:475-483.

\section{INTRODUCTION}

Mutations in the coding region of the methyl-CpG-binding protein 2 gene (MECP2) are responsible for about $80 \%$ of Rett Syndrome (RTT, OMIM \#312750) cases [Amir et al., 1999]. Most RTT patients develop microcephaly, seizures, and autism. Autism (OMIM \#209850) is a neurodevelopmental disorder characterized by deficits in social interaction and communication, and by restricted and stereotyped patterns of behavior. It affects more males than females, in a ratio of $3-4: 1$, which led to the hypothesis of the involvement of an X-linked gene. As autism and RTT share a range of symptoms, it was speculated that specific mutations in the $M E C P 2$ coding region could also be involved in autism etiology. Evidence for linkage to autism was recently found at chromosome Xq27-q28, in the region where MECP2 maps, supporting it as a candidate gene for this disorder [Vincent et al., 2005]. So far, a number of mutations previously found in RTT have been reported in autism studies [van Karnebeek et al., 2002; Carney et al., 2003; Lobo-Menendez et al., 2003; Zappella et al., 2003]. In two studies novel alterations were reported, one missense change in one autistic male [Beyer et al., 2002] and a de novo intronic variation in an autistic female with mental retardation [Lam et al., 2000], although their functional significance was not demonstrated. Mutations in MECP2 have also been found in other syndromes, including non-specific X-linked mental retardation in males (reviewed in Bienvenu and Chelly [2006]). Although severe MECP2 mutations leading to RTT are thought to be lethal in hemizygous males, these studies 
show the existence of sequence changes not found in RTT that segregate in the families of males with autism, mental retardation, and occasionally language problems. Hemizygosity for some $M E C P 2$ mutations, leading to a less severe functional alteration of the protein, may therefore be compatible with life, with heterozygosity for these same mutations insufficient to cause disease in the female carriers.

The MECP2 gene originates two protein isoforms: MeCP2 e2, encoded by exons 2-4, and MeCP2 e1, encoded by exons 1,3 , and 4 , which is more abundantly expressed in the brain [Kriaucionis and Bird, 2004; Mnatzakanian et al., 2004]. $\mathrm{MeCP} 2$ acts as a transcriptional repressor and is mainly expressed in the central nervous system (CNS), indicating a role in the regulation of brain gene expression. Although its target genes are not fully known, microarray studies have found several genes with altered expression in RTT, some showing a direct regulation by MeCP2 (reviewed in Bienvenu and Chelly [2006]). In addition, it has been demonstrated that it regulates the expression of the brain-derived neurotrophic factor gene $(B D N F)$, which encodes a molecule essential in neurodevelopment and neuronal plasticity, learning, and memory [Chen et al., 2003; Martinowich et al., 2003]. The $3^{\prime} \mathrm{UTR}$ in exon 4 is unusually long $(8.5 \mathrm{~kb})$ and well conserved between human and mouse, with at least eight blocks of strong sequence similarity that can represent important functional domains [Coy et al., 1999]. The size and conservation of this region, as well as expression studies in post-mortem brain, indicate an important role in the transcriptional regulation of MECP2. Samaco et al. [2004] found altered levels of MECP2 expression in the brain of four out of five autistic individuals, none of which had mutations in the coding region of $M E C P 2$, suggesting that variations in the $5^{\prime} \mathrm{UTR}$ or $3^{\prime} \mathrm{UTR}$ could be responsible for these changes. These findings support the hypothesis that variants in the $3^{\prime} \mathrm{UTR}$, and not only in the coding region of $M E C P 2$, may be involved in some clinical manifestations.

A previous report has shown a higher frequency of missense and $3^{\prime} \mathrm{UTR}$ variants in a sample of 24 autistic patients, as compared to other psychiatric diseases [Shibayama et al., 2004]. In the present study, we extend the search for MECP2 mutations in the coding region, exon-intron boundaries, and in the whole $3^{\prime}$ UTR in 172 patients with autism. Our goal was to determine if the phenotypic spectrum of mutations extends beyond the traditional diagnosis in RTT and mental retardation, leading to a less severe phenotype in autistic male and female patients.

\section{MATERIALS AND METHODS}

\section{Subjects and Clinical Assessments}

One hundred seventy two caucasian unrelated autistic children (141 males and 31 females; age range of $2-14$ years old), originating from mainland Portugal and the Azorean islands, were recruited at the Autism Clinic from Hospital Pediátrico de Coimbra (HP). Diagnosis and assessment of the children followed a comprehensive evaluation protocol by a clinical team including a developmental pediatrician, two psychologists, one special education teacher, and a social worker. Observation of the children entailed extensive interaction and semi-structured activities in a clinical setting. ASD was diagnosed using DSM-IV (American Psychiatric Association 1994) criteria, the Autism Diagnostic Interview-Revised (ADI-R) [Lord et al., 1994], and the Childhood Autism Rating Scale (CARS) [Schopler et al., 1988]. Diagnosis required fulfillment of DSM-IV criteria and meeting the ADI-R algorithm cutoff for autistic disorder, and a functional level of 12 months or above. Consensus diagnosis among the clinical team was obtained for all patients. About $90 \%$ of these patients are routinely followed by the same clinical team at HP and therefore are monitored over several years until age 18 .

Developmental or intellectual quotients were determined using the Ruth Griffiths Mental Development Scale II [Griffiths, 1984] or the Wechsler Intelligence Scale for Children (WISC 1974). Functional level was assessed using the Vineland Scales for Adaptive Behavior [Carter et al., 1998]. Idiopathic subjects were included after clinical assessment and screening for known medical and genetic conditions associated with autism, including testing for Fragile X mutations (FRAXA and FRAXE), chromosomal abnormalities (karyotype study), neurocutaneous syndromes, endocrine, and metabolic disorders. Control Portuguese unrelated adult individuals consisted of 143 caucasian healthy blood donors (113 males and 30 females), with no family history of neuropsychiatric diseases. Control Portuguese unrelated children consisted of 36 healthy individuals ( 21 males and 15 females; age range of 2-15 years old), recruited at the surgery service at the HP where they were undergoing minor surgery procedures, requiring blood sample collection for pre-surgery baseline evaluation. The study was approved by the HP ethical committee, and all participants or legal representatives signed an informed consent.

\section{MECP2 Mutation Detection}

The coding region of $M E C P 2$ comprising exons 2-4, exonintron boundaries, and its whole $3^{\prime} \mathrm{UTR}$, were scanned for mutations with Detection Of Virtually All Mutations-SSCP (DOVAM-S) [Liu et al., 1999]. DOVAM-S is a robotically enhanced and highly redundant form of Single Strand Conformational Polymorphism (SSCP) with virtually 100\% sensitivity of mutation detection. The gene was first amplified robotically in 42 segments ranging in size from 150 to $476 \mathrm{bp}$, pooled, denatured, and electrophoresed under five nondenaturing conditions varying in gel matrix, buffer, temperature, and additive. PCR products with mobility shifts were sequenced with the ABI model 377 (Perkin-Elmer Model 377, Norwalk, CT) and nucleotide alterations were analyzed with Sequencher 4.1 software (Gene Codes, Ann Arbor, MI). Sequence changes were confirmed by reamplification with genomic DNA and sequencing in the opposite direction. Exon 1 was analyzed by direct sequencing of the corresponding region. Information on the primers used for amplification of the coding region and the $3^{\prime} \mathrm{UTR}$ of $M E C P 2$, as well as the PCR conditions used, is provided on the Supplementary Information section.

\section{Bioinformatic Analysis of the $M E C P 2$ Sequence}

In order to assess if the novel intronic changes were affecting normal splicing by altering a consensus sequence, the program GenScan version 1.0 was used, which performs predictions of exon/intron splice sites based on local nucleotide sequence properties of the genomic DNA. Protein secondary structure predictions were performed for the novel missense changes found in MECP2 using the programs PeptideStructure (GCG package, version 10.0), Garnier (Emboss, version 2.8.0), and SSpro8, which use several algorithms for prediction based on the primary structure and properties of the amino acid residues. Searching for sequence patterns in the $3^{\prime}$ UTR of MECP2 was performed using UTRscan database, which looks for known UTR functional elements, and the program FindPatterns (GCG package, version 10.0), which locates short sequence patterns specified by the user.

\section{RNA Isolation and Quantification of the MECP2 mRNA}

Total RNA was extracted from $5 \times 10^{6}$ peripheral blood mononuclear cells (PBMCs) using the RNeasy Mini Kit (Qiagen, Valencia, CA), and used for amplification of the first 
strand of cDNA by reverse transcription with oligo-dT primer (Invitrogen, Carlsbad, CA). Total MECP2 mRNA (MECP2_e1 and MECP2 e2 transcripts) levels were quantified by quantitative PCR with LightCycler Fast Start SYBR Green I (Roche Molecular Biochemicals, Mannheim, Germany). For each sample, $50 \mathrm{ng}$ of first-stranded cDNA were amplified in duplicate by PCR and real-time fluorimetric intensity of SYBR green I was monitored. The levels of MECP2 mRNA for each sample were normalized by the amount of mRNA of the housekeeping gene HPRT1. Details for the quantitative PCR reaction, including primers used for MECP2 and HPRT1 are provided in the Supplementary Information section.

\section{Quantitative X-chromosome Inactivation Assay}

$\mathrm{X}$-chromosome inactivation (XCI) assays were performed in DNA isolated from peripheral blood leukocytes, to assess the pattern of XCI in the carrier mother and maternal grandmother of the autistic male who presented the novel p.G206A missense change. It was also performed in the proband, in order to determine which allele was inherited from his mother. The assay was based on a previously described method [Allen et al., 1992], which allows the determination of the Xinactivation status using a trinucleotide repeat polymorphism in the androgen receptor gene $(A R)$ flanked by two methylation-sensitive restriction enzyme sites. These sites are methylated on the inactive $\mathrm{X}$ chromosome, and are unmethylated on the active $\mathrm{X}$ chromosome. This allowed the development of an assay that distinguishes between the maternal and paternal alleles (through the repeat number) and identifies their methylation status (through enzymatic restriction). Details for the assay are provided in the Supplementary Information section.

\section{Quantification of BDNF Levels in Plasma}

Levels of BDNF were quantified in plasma using BDNF Emax Immunoassay System kit (Promega Corp., Madison, WI), according to the manufacturer's instructions. The assays were performed in duplicate for each sample.

\section{RESULTS \\ Variation of the MECP2 Coding Region and Exon-Intron Boundaries in Autistic Patients and Controls}

Scanning of MECP2 sequence changes in exons 2-4 and exon-intron boundaries was performed in 172 patients (141 males and 31 females; $203 \mathrm{X}$-chromosomes total), revealing that 12 patients $(7.0 \%), 10$ males and 2 females, have sequence changes corresponding to 11 different variants (Table I). Of these, four are missense changes observed in males, of which one is novel. In addition, we found four silent and three intronic changes (two novel); of these, two silent and one intronic change were also present in the controls, and have been previously reported [Trappe et al., 2001; Kleefstra et al., 2004]. The novel missense change is a c. $617 \mathrm{G}>\mathrm{C}$ transition found in one autistic male, resulting in a p.G206A amino acid replacement in the inter-domain region of MeCP2, and was not found in 143 controls. Protein secondary structure predictions revealed that this alteration can disturb a $\alpha$-helix in the inter-domain region of the protein, due to the alteration in amino acid properties from polar to hydrophobic. This amino acid position is included in a region involved in a histone deacetylase-independent pathway of transcriptional repression by MeCP2 [Yu et al., 2000], and thus this sequence change is likely to lead to an alteration in protein function. Predictions of exon/intron splice sites were performed for the novel intronic changes found, and do not alter any putative consensus sequence in the genomic DNA, therefore it is not likely that they affect normal splicing of MECP2. None of the sequence variants found in our autistic children sample have been reported as pathogenic mutations in Rett syndrome studies. Sequencing of exon 1 was performed in 103 autistic patients (88 males and 15 females; $118 \mathrm{X}$-chromosomes total), and no sequence changes were found, indicating that alterations in this region in autistic patients are likely very rare.

In 143 Portuguese healthy controls (113 males and 30 females; $173 \mathrm{X}$-chromosomes total), we found 11 individuals $(7.7 \%), 5$ males and 6 females, with sequence changes in exons 2-4 and exon-intron boundaries, corresponding to six distinct variants (Table II). Of these, one is a novel missense change (p.K82R) occurring in one male, one intronic change, and four silent changes. The p.K82R missense change does not lead to a change in amino acid properties and does not alter the secondary structure of the protein, so it likely represents a rare polymorphism. None of the sequence variants found in the control samples have been reported as pathogenic mutations in previous studies. Of the sequence changes observed in this study, three were common to both patients and controls (c.378-19delT, p.A131A, and p.T445T), suggesting that they are polymorphisms with no pathogenic effect, as reported before [Trappe et al., 2001; Kleefstra et al., 2004].

\section{Variation of the MECP2 $3^{\prime}$ UTR in Autistic Patients and Controls}

Scanning of mutations was performed in the whole $3^{\prime} \mathrm{UTR}$ of MECP2. We found 46 patients out of $172(26.7 \%)$ with $3^{\prime} \mathrm{UTR}$ variations, some having more than one change. In total, 24 unique sequence changes were found (13 in conserved nucleotides), of which 21 are novel (Table III). In 96 Portuguese controls (76 males and 20 females; $116 \mathrm{X}$-chromosomes total) we observed 26 individuals $(27.1 \%)$ with $3^{\prime}$ UTR variations, in a total of 20 unique sequence changes (12 in conserved nucleotides) (Table IV). Again, some of the individuals had more than one sequence change, indicating that there is a high variability in the $3^{\prime}$ UTR. All of the variations encountered were novel, except the c.9964insC [Bourdon et al., 2001]. Ten of the changes were common to both patients and controls, suggesting that they do not have any pathogenic effect. A high degree of sequence variability in the $3^{\prime}$ UTR was found, comparable in patients and controls, even in the most conserved regions between human and mouse. However, of the 21 novel changes found in patients, 12 were not present in the controls. Of these, seven were located in conserved nucleotides in seven autistic males, and only one was found in one autistic female: c. $4167 \mathrm{G}>\mathrm{A}$ (heterozygous). One of these novel changes, c. $1655 \mathrm{G}>\mathrm{A}$, was localized in a region of strong sequence identity with mouse, suggesting that it may alter the regulation of MECP2 expression.

Little is known about the functionality of the long $3^{\prime} \mathrm{UTR}$ of MECP2. In order to understand the meaning of the alterations found in this study we performed scans for known sequence patterns in $3^{\prime} \mathrm{UTR}$ regions. We found eight matches for 15lipoxygenase differentiation control elements (15-LOX-DICE), which are CU-rich sequences involved in mRNA stabilization and translation inhibition, and at least two matches for AUrich elements (AREs) and several C-rich regions, involved in the regulation of mRNA stability. However, none of the $3^{\prime} \mathrm{UTR}$ alterations found exclusively in the patients were localized within any of these regions. MECP2 mRNA levels were measured in PBMCs from four autistic males presenting changes in conserved nucleotides: c. $1832 \mathrm{G}>\mathrm{C}$, c.2015G $>\mathrm{A}$, c. $4017 \mathrm{~T}>\mathrm{A}$, and c. $4417 \mathrm{G}>\mathrm{A}$ (Fig. 1). $M E C P 2$ mRNA levels measured in four autistic males in the same age range, but without any detected $M E C P 2$ alteration, were used as controls for specificity of these MECP2 changes within the autistic 
Coutinho et al.

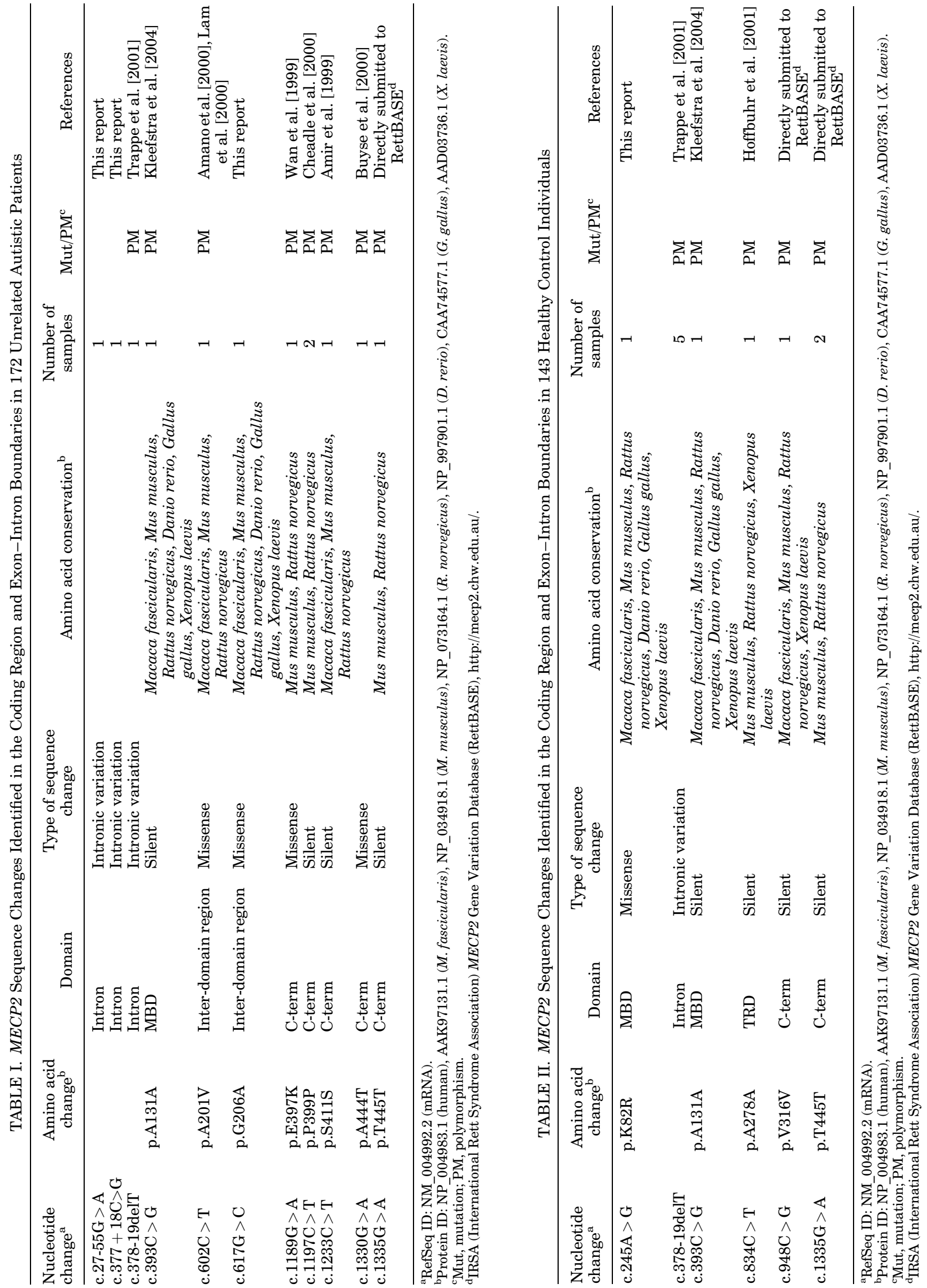


TABLE III. MECP2 3'UTR Variants Identified in 172 Unrelated Autistic Patients

\begin{tabular}{|c|c|c|c|c|}
\hline $\begin{array}{l}\text { Nucleotide } \\
\text { change }^{\mathrm{a}}\end{array}$ & $\begin{array}{l}\text { Nucleotide } \\
\text { conservation }^{\mathrm{a}}\end{array}$ & $\begin{array}{l}\text { Number of } \\
\text { samples }\end{array}$ & $\mathrm{Mut} / \mathrm{PM}^{\mathrm{b}}$ & References \\
\hline c. $1470 \mathrm{G}>\mathrm{A}$ & & 1 & PM & Lam et al. [2000] \\
\hline c. $1554 \mathrm{G}>\mathrm{A}$ & Mus musculus & 1 & PM & Ylisaukko-Oja et al. [2005] \\
\hline c. $1655 \mathrm{G}>\mathrm{A}$ & Mus musculus & 1 & & This report \\
\hline c. $1832 \mathrm{G}>\mathrm{C}$ & Mus musculus & 1 & & This report \\
\hline c. $2005 \mathrm{G}>\mathrm{A}$ & & 1 & & This report \\
\hline c. $2015 \mathrm{G}>\mathrm{A}$ & Mus musculus & 1 & & This report \\
\hline c. $2228 \mathrm{G}>\mathrm{T}$ & & 1 & & This report \\
\hline c. $2322 \mathrm{~T}>\mathrm{G}$ & Mus musculus & 1 & & This report \\
\hline c. $2339 \mathrm{C}>\mathrm{G}$ & & 15 & & This report \\
\hline c. $2829 \mathrm{C}>\mathrm{A}$ & Mus musculus & 1 & & This report \\
\hline c. $3198 \mathrm{G}>\mathrm{A}$ & Mus musculus & 8 & & This report \\
\hline c. $4017 \mathrm{~T}>\mathrm{A}$ & Mus musculus & 1 & & This report \\
\hline c. $4118 \mathrm{G}>\mathrm{A}$ & & 1 & & This report \\
\hline c. $4167 \mathrm{G}>\mathrm{A}$ & & 1 & & This report \\
\hline c. $4417 \mathrm{G}>\mathrm{A}$ & Mus musculus & 1 & & This report \\
\hline c. $4938 \mathrm{G}>\mathrm{A}$ & & 2 & & This report \\
\hline c. $5119 \mathrm{C}>\mathrm{T}$ & & 1 & & This report \\
\hline c. $5339 \mathrm{G}>\mathrm{C}$ & & 1 & & This report \\
\hline c. $6037 \mathrm{~A}>\mathrm{C}$ & Mus musculus & 1 & & This report \\
\hline c.6948ins (AT) & Mus musculus & 1 & & This report \\
\hline c. $9209 \mathrm{C}>\mathrm{T}$ & Mus musculus & 1 & & This report \\
\hline c. $9317 \mathrm{~A}>\mathrm{C}$ & Mus musculus & 13 & & This report \\
\hline c. $9964 \mathrm{delC}$ & & 2 & & This report \\
\hline c.9964insC & & 3 & $\mathrm{PM}$ & Bourdon et al. [2001] \\
\hline
\end{tabular}

${ }^{a}$ RefSeq ID: NM_004992.2 (human), AF158181.1 (M. musculus).

${ }^{\mathrm{b}}$ Mut, mutation; $\mathrm{PM}$, polymorphism.

phenotype. MECP2 mRNA levels of the patients with $3^{\prime} \mathrm{UTR}$ changes were significantly lower when compared with these controls (Kruskal-Wallis test, $P=0.021$ ). Although mRNA levels were measured in very few individuals, all four patients with $3^{\prime}$ UTR alterations had lower levels than any of the patients with no MECP2 sequence changes (Fig. 1), suggesting that at least these alterations in $3^{\prime}$ UTR conserved nucleotides may render the $M E C P 2$ transcripts more unstable and subject to degradation.

\section{Analysis of the Novel p.G206A Missense Change}

Segregation analysis was carried out in the family of the autistic male in which the novel p.G206A missense change was found (Fig. 2A). Clinical, neuropsychological, and behavioral data on this patient is shown in Table $\mathrm{V}$. This patient was 10 years old at the time of collection, and had severe autism (positive ADI-R and DSM-IV with a CARS score of 50.5), severe mental retardation (Global Developmental Quotient of

TABLE IV. MECP2 3'UTR Variants Identified in 96 Healthy Control Individuals

\begin{tabular}{|c|c|c|c|c|}
\hline Nucleotide change $^{a}$ & $\begin{array}{l}\text { Nucleotide } \\
\text { conservation }^{\mathrm{a}}\end{array}$ & $\begin{array}{l}\text { Number of } \\
\text { samples }\end{array}$ & Mut/PM ${ }^{\mathrm{b}}$ & Reference \\
\hline c. $1854 \mathrm{G}>\mathrm{A}$ & & 1 & & This report \\
\hline c. $1950 \mathrm{G}>\mathrm{C}$ & Mus musculus & 1 & & This report \\
\hline c. $1990 \mathrm{G}>\mathrm{T}$ & Mus musculus & 1 & & This report \\
\hline c. $2267 \mathrm{G}>\mathrm{A}$ & Mus musculus & 1 & & This report \\
\hline c. $2292 \mathrm{G}>\mathrm{C}$ & Mus musculus & 1 & & This report \\
\hline c.2336insA & & 1 & & This report \\
\hline c. $2339 \mathrm{C}>\mathrm{G}$ & & 8 & & This report \\
\hline c. $2698 \mathrm{~T}>\mathrm{C}$ & Mus musculus & 1 & & This report \\
\hline c. $3198 \mathrm{G}>\mathrm{A}$ & Mus musculus & 5 & & This report \\
\hline c. $4938 \mathrm{G}>\mathrm{A}$ & & 3 & & This report \\
\hline c. $5123 \mathrm{~A}>\mathrm{G}$ & Mus musculus & 1 & & This report \\
\hline c. $5339 \mathrm{G}>\mathrm{C}$ & & 1 & & This report \\
\hline c.5547del(GT) & & 1 & & This report \\
\hline c. $6037 \mathrm{~A}>\mathrm{C}$ & Mus musculus & 2 & & This report \\
\hline c. $6948 \mathrm{ins}(\mathrm{AT})$ & Mus musculus & 1 & & This report \\
\hline c. $7300 \mathrm{C}>\mathrm{T}$ & Mus musculus & 1 & & This report \\
\hline c. $9209 \mathrm{C}>\mathrm{T}$ & Mus musculus & 1 & & This report \\
\hline c. $9317 \mathrm{~A}>\mathrm{C}$ & Mus musculus & 5 & & This report \\
\hline c.9964delC & & 5 & & This report \\
\hline c.9964insC & & 2 & PM & Bourdon et al. [2001] \\
\hline
\end{tabular}

${ }^{a}$ RefSeq ID: NM 004992.2 (human), AF158181.1 (M. musculus).

${ }^{\mathrm{b}}$ Mut, mutation; $\mathrm{PM}$, polymorphism. 


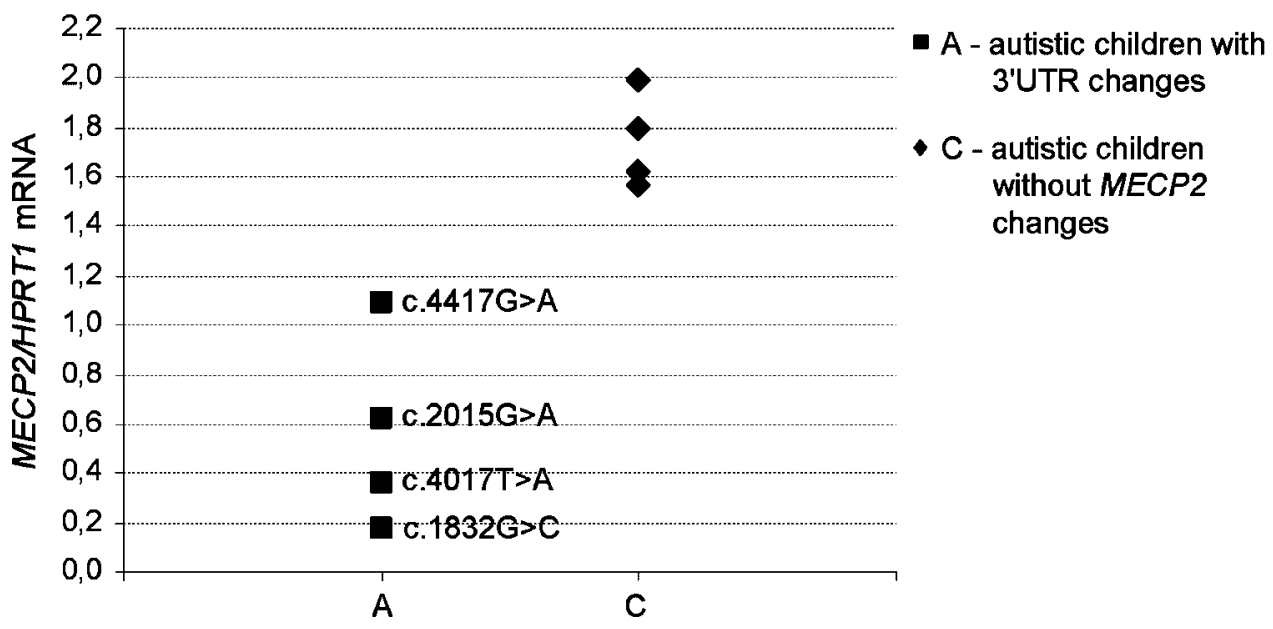

Fig. 1. MECP2 mRNA quantification in PBMCs from four autistic males with different $3^{\prime} \mathrm{UTR}$ alterations in conserved nucleotides: c. $1832 \mathrm{G}>\mathrm{C}$, c. $2015 \mathrm{G}>\mathrm{A}$, c.4017T > A, and c.4417G > A, compared with four autistic males without MECP2 changes. Results were normalized for HPRT1 mRNA levels.

25), and absence of language. He had purposeful hand manipulation of objects and hand stereotypies not characteristic of Rett syndrome. Breathing irregularities were never noticed by the family and he never had epilepsy. In the first year of life he had developmental delay without history of

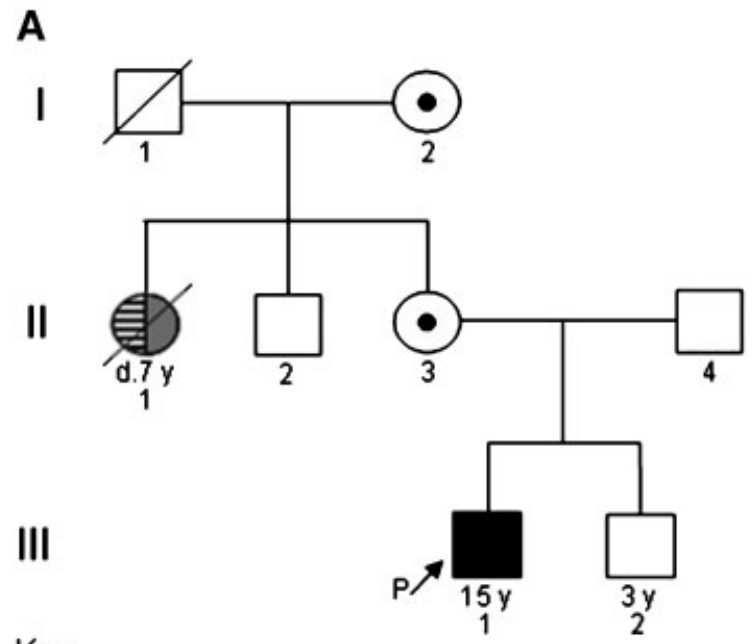

regression, the weight and height were in the percentile 5 , and the cephalic perimeter was in the percentile 50 (without posterior deceleration of head growth). Presently 15 years old, he shows the same symptomatology and his neurologic examination does not show any abnormality besides mental retardation and autistic behavior. This patient has a younger male sibling who is 3 years of age and has a normal development to this day. A maternal aunt died at age 7 and was reported to have mental retardation, abnormal motor development, and uncontrolled seizures of unknown etiology. The available relatives from the proband were sequenced for the p.G206A alteration: his parents, the maternal grandmother, and a maternal uncle (see Fig. 2A). The mother and maternal grandmother are heterozygous asymptomatic carriers of this sequence change. Quantitative XCI assays were then performed in the female relatives; the proband was also tested, to determine which of the alleles was inherited from his mother. A pattern of moderately skewed XCI ratio of $\pm 30 \%: 70 \%$ was found in the mother, and a normal random pattern of $\pm 40 \%: 60 \%$ was found in the grandmother (Fig. $2 \mathrm{~B}$ ). Although the three individuals (proband, mother, and maternal grandmother) share the same alteration, they do not share one common androgen receptor gene $(A R)$ allele. Because $A R$ (Xq12) and MECP2 (Xq28) are located far apart in the X chromosome, this suggests that a crossing-over event has occurred between generations. If this is correct, the mutation must be segregating with the low molecular weight allele from the grandmother to the mother (allele $\mathrm{c}$ in Fig. 2B), and then passed to the proband together with the intermediate molecular weight allele (allele b in Fig. 2B), due to recombination in the mother's germline. Densitometry analysis shows that in the mother, who inherited the mutated MECP2 allele from the grandmother (associated with allele c in Fig. 2B), the $\mathrm{X}$ chromosome carrying the wild type $M E C P 2$ allele (inherited

Fig. 2. Pedigree and X-chromosome inactivation (XCI) assay results in the family of the autistic proband who presents the novel p.G206A missense change in MECP2. Panel A: pedigree showing the structure of the family of the autistic patient in whom the novel p.G206A missense change was found. Panel B: XCI assay results, performed in leukocytes of the autistic proband with the p.G206A alteration and the family female carriers; the autoradiography shows the $A R$ allelic band pattern after PCR amplification of the DNA samples. III.1-proband; II.3-proband's mother; I.2-proband's maternal grandmother; A-PCR amplification after restriction of genomic DNA with $H$ haI (only methylated, inactivated alleles are amplified); BPCR amplification of intact genomic DNA; C-PCR amplification with no DNA (negative control); a, b, c- $-A R$ trinucleotide repeat alleles. 
TABLE V. Clinical, Neuropsychological, and Behavioral Data of the Patient Presenting the p.G206A Missense Change in MECP2

\begin{tabular}{|c|c|}
\hline Variable & Clinical data \\
\hline Age at examination (years) & 10 \\
\hline \multicolumn{2}{|l|}{ Physical measurements } \\
\hline Height & 5 th percentile \\
\hline Occipital-frontal circumference (OFC) & 50th percentile \\
\hline Weight & 5 th percentile \\
\hline \multicolumn{2}{|l|}{ Neurological symptoms } \\
\hline Seizures & No \\
\hline Brisk tendon reflexes & No \\
\hline Tremor & No \\
\hline \multicolumn{2}{|l|}{ Developmental history } \\
\hline First remarkable signs of autism (months) & $<12$ \\
\hline Walked independently (months) & 12 \\
\hline \multicolumn{2}{|l|}{ Motor skills } \\
\hline Poor-motor coordination & No \\
\hline Slow & No \\
\hline Clumsy & No \\
\hline Regression & No \\
\hline Sleep problems & No \\
\hline \multicolumn{2}{|l|}{ Developmental quotient (Ruth Griffiths Mental Development Scale II) } \\
\hline Global developmental quotient (GDQ) & 25 \\
\hline Motor developmental quotient (MDQ) & 30 \\
\hline Performance developmental quotient (PDQ) & 23 \\
\hline Language developmental quotient (LDQ) & 13 \\
\hline \multicolumn{2}{|l|}{ Vineland adaptive behavior scales domain scores } \\
\hline Communication (percentile rank ${ }^{\mathrm{a}}$ ) & 40 \\
\hline Daily living (percentile rank ${ }^{a}$ ) & 50 \\
\hline Socialization (percentile rank ${ }^{\mathrm{a}}$ ) & 40 \\
\hline Adaptive behavior composite (percentile rank ${ }^{a}$ ) & 50 \\
\hline \multicolumn{2}{|l|}{ DSM-IV positive criteria } \\
\hline Qualitative impairment in social interaction & 3 out of 4 \\
\hline Qualitative impairments in communication & 2 out of 4 \\
\hline $\begin{array}{l}\text { Restricted repetitive and stereotyped patterns of behavior, interests, and } \\
\text { activities }\end{array}$ & 4 out of 4 \\
\hline $\begin{array}{l}\text { Delays or abnormal functioning, with onset prior to age } 3 \text { years, in social } \\
\text { interaction, language and symbolic or imaginative play }\end{array}$ & Yes \\
\hline Disturbance not better accounted for by Rett's disorder or CDD & No \\
\hline \multicolumn{2}{|l|}{ ADI-R domain scores at final diagnosis } \\
\hline Social interaction $($ cutoff $=10 ; \max .=30)$ & 29 out of 30 \\
\hline Communication: nonverbal $($ cutoff $=7 ;$ max. $=14$ ) & 13 out of 14 \\
\hline Repetitive behavior $($ cutoff $=3 ; \max .=12$ ) & 4 out of 12 \\
\hline
\end{tabular}

from her father, associated with allele $b$ in Fig. 2B), is preferentially inactivated. Because both the mother and maternal grandmother show a normal phenotype, any pathogenic effect of the p.G206A missense change can likely be compensated by the expression of the normal allele in the carrier females.

In view of these results, we evaluated the role of the p.G206A missense change in the functionality of MeCP2. Because $B D N F$ is one of the few genes known to be directly regulated by MeCP2 [Chen et al., 2003; Martinowich et al., 2003], we quantified plasma BDNF levels in this autistic patient $(19.5 \mathrm{ng} /$ $\mathrm{ml}$ ), which were found to be within normal levels when compared to 36 age-matched control children (range: 8.9$69.8 \mathrm{ng} / \mathrm{ml}$; mean: $28.6 \mathrm{ng} / \mathrm{ml} \pm 13.9 \mathrm{SD}$ ). This result suggests that the potential pathogenic mechanism of this missense change does not involve BDNF level changes in this patient, or that they are too mild in plasma to be detected at this level.

\section{DISCUSSION}

In the present study we hypothesized that sequence changes in specific locations within the MECP2 gene that are less deleterious for MeCP2 function might be involved in a pathway leading to a milder, non-lethal phenotype in autistic male and female patients, extending beyond the traditional RTT diagnosis.

We found low sequence variability in the coding region and exon-intron boundaries of $M E C P 2$, comparable in autistic patients $(7.0 \%)$ and controls $(7.7 \%)$, in agreement with previous studies in which $M E C P 2$ sequence changes were found only rarely in subjects with autism [Lam et al., 2000; Beyer et al., 2002; van Karnebeek et al., 2002; Carney et al., 2003; Lobo-Menendez et al., 2003; Zappella et al., 2003; Shibayama et al., 2004]. We report two intronic variations and one missense change that were not present in the control sample. The novel missense change (p.G206A) was found in one autistic male, and segregates in his family. It is localized in a highly conserved amino acid, within a region implicated in an alternative transcriptional repression pathway independent of histone-deacetylation [Yu et al., 2000], and likely leads to a change in protein structure, implying that it may alter the function of MeCP2. These findings are compatible with an association of this change with autism in the proband. In the proband's mother and grandmother, who have a normal phenotype, either the MECP2 mutated allele has a low penetrance or its deleterious effect is compensated by the 
expression of the normal allele, which may be sufficient to avoid the appearance of symptoms. It is possible that the maternal aunt, affected with mental retardation, and who died early in life, had the p.G206A alteration with a skewed XCI favoring the expression of the mutated allele. Plasma BDNF levels of the autistic proband were found to be within normality, suggesting that the pathogenic mechanism does not involve BDNF level changes in this patient. However, we cannot exclude that an alteration in BDNF levels in the CNS mediated by the altered MeCP2 is not accompanied by a change in plasma levels. The expression of other target genes which may be involved in the clinical phenotype of this patient was not investigated.

We sequenced exon 1 of $M E C P 2$ in 103 autistic patients, and found no sequence changes in this region. Mutations in exon 1, and thus in MeCP2_e1, either do not play a role in autism etiology or occur very rarely associated with this disorder, possibly with a very severe effect.

To our knowledge, this is the first report in which the whole $3^{\prime} \mathrm{UTR}$ of $M E C P 2$ was scanned for sequence variations. We found a high degree of sequence variability in the $3^{\prime} \mathrm{UTR}$, comparable between patients $(26.7 \%)$ and controls $(27.1 \%)$. In 172 patients, 12 novel changes were found, of which 7 were located in conserved nucleotides. In the patients carrying four of these conserved $3^{\prime} \mathrm{UTR}$ alterations MECP2 mRNA levels were always lower that in autistic patients without any $M E C P 2$ sequence changes. While the use of autistic individuals with no $M E C P 2$ alterations as controls does not provide us with the normal range of mRNA levels, it suggests that lower expression, and a consequent abnormal overexpression of target genes, may be a specific cause of autism for the individuals bearing these $M E C P 2$ sequence alterations, among autistic individuals. Given the etiological heterogeneity of autism, with multiple genetic alterations known to lead to an autistic phenotype, this hypothesis is plausible. These results are however to be considered preliminary, as the sample size is very small. If confirmed in a larger sample, these observations would indicate the existence of important regulatory regions within the $3^{\prime} \mathrm{UTR}$ of $M E C P 2$.

Taken together, our results suggest that mutations in the $M E C P 2$ coding region and $3^{\prime} \mathrm{UTR}$ alterations in conserved regions may play only a minor role in autism etiology. We report a novel missense change, which may have a non-lethal but severe pathogenic effect in males. Functional studies in order to demonstrate its pathogenicity are under way. Mutations in the coding region, however, are probably restricted to a very small subgroup of subjects with autism, as we found only one patient out of $172(0.58 \%)$ with a potential pathogenic mutation; if we consider exclusively the autistic male sample $(n=141)$, this frequency increases to $0.71 \%$. Additionally, we report seven novel $3^{\prime}$ UTR alterations in conserved nucleotides, present in seven autistic males out of 172 patients $(4.07 \% ; 4.96 \%$ in the male sample), of which at least four possibly alter the stability of the MECP2 transcripts. The frequency of MECP2 alterations in autism might be higher, as we did not scan the promoter region and the method used cannot detect large deletions or duplications that could be missed in heterozygous females (and duplications in males). Our patient sample included only idiopathic cases, which were screened for common medical conditions associated with autism including tuberous sclerosis, Fragile $\mathrm{X}$ syndrome, and chromosomal abnormalities, as a standard procedure. The prevalence of these conditions in autism spectrum disorders is estimated to be $1-3 \%, 2-3 \%$, and $5 \%$, respectively [Rutter, 2005], with full mutations of the gene causing the Fragile $X$ syndrome (FMR1) observed in less than $1 \%$ of children with autism [Lord et al., 2000]. Similarly, rare mutations in MECP2 may increase the susceptibility to develop autism in a minority of cases. Screening for MECP2 mutations in cases of autism associated with mental retardation, particularly in males who may have a variable phenotype, may be useful for research purposes, to decrease genetic heterogeneity in the study samples and thus facilitate the identification of other genes predisposing to autism.

\section{ACKNOWLEDGMENTS}

We thank the autistic patients and their relatives for their collaboration in this study. This work was supported by grants from Fundação Calouste Gulbenkian (FCG) and Fundação para a Ciência e a Tecnologia (FCT) (POCTI/39636/ESP/2001), Portugal. Ana M. Coutinho and Mónica Santos were supported by Ph.D. fellowships from FCT (SFRH/BD/3145/2000 and SFRH/BD/9111/2002, respectively) and from Fundo Social Europeu (III Quadro Comunitário de Apoio).

\section{References}

Allen RC, Zoghbi HY, Moseley AB, Rosenblatt HM, Belmont JW. 1992 Methylation of HpaII and HhaI sites near the polymorphic CAG repeat in the human androgen-receptor gene correlates with $\mathrm{X}$ chromosome inactivation. Am J Hum Genet 51:1229-1239.

Amano K, Nomura Y, Segawa M, Yamakawa K. 2000. Mutational analysis of the MECP2 gene in Japanese patients with Rett syndrome. J Hum Genet 45:231-236.

Amir RE, Van den Veyver IB, Wan M, Tran CQ, Francke U, Zoghbi HY. 1999. Rett syndrome is caused by mutations in X-linked MECP2, encoding methyl-CpG-binding protein 2. Nat Genet 23:185-188.

Beyer KS, Blasi F, Bacchelli E, Klauck SM, Maestrini E, Poustka A. 2002. Mutation analysis of the coding sequence of the MECP2 gene in infantile autism. Hum Genet 111:305-309.

Bienvenu T, Chelly J. 2006. Molecular genetics of Rett syndrome: When DNA methylation goes unrecognized. Nat Rev Genet 7:415-426.

Bourdon V, Philippe C, Labrune O, Amsallem D, Arnould C, Jonveaux P. 2001. A detailed analysis of the MECP2 gene: Prevalence of recurrent mutations and gross DNA rearrangements in Rett syndrome patients. Hum Genet 108:43-50.

Buyse IM, Fang P, Hoon KT, Amir RE, Zoghbi HY, Roa BB. 2000. Diagnostic testing for Rett syndrome by DHPLC and direct sequencing analysis of the MECP2 gene: Identification of several novel mutations and polymorphisms. Am J Hum Genet 67:1428-1436.

Carney RM, Wolpert CM, Ravan SA, Shahbazian M, Ashley-Koch A, Cuccaro ML, Vance JM, Pericak-Vance MA. 2003. Identification of MeCP2 mutations in a series of females with autistic disorder. Pediatr Neurol 28:205-211.

Carter AS, Volkmar FR, Sparrow SS, Wang JJ, Lord C, Dawson G, Fombonne E, Loveland K, Mesibov G, Schopler E. 1998. The Vineland Adaptive Behavior Scales: Supplementary norms for individuals with autism. J Autism Dev Disord 28:287-302.

Cheadle JP, Gill H, Fleming N, Maynard J, Kerr A, Leonard H, Krawczak M, Cooper DN, Lynch S, Thomas N, Hughes H, Hulten M, Ravine D, Sampson JR, Clarke A. 2000. Long-read sequence analysis of the MECP2 gene in Rett syndrome patients: Correlation of disease severity with mutation type and location. Hum Mol Genet 9:11191129

Chen WG, Chang Q, Lin Y, Meissner A, West AE, Griffith EC, Jaenisch R, Greenberg ME. 2003. Derepression of BDNF transcription involves calcium-dependent phosphorylation of MeCP2. Science 302 : $885-889$.

Coy JF, Sedlacek Z, Bachner D, Delius H, Poustka A. 1999. A complex pattern of evolutionary conservation and alternative polyadenylation within the long 3'-untranslated region of the methyl-CpG-binding protein 2 gene (MeCP2) suggests a regulatory role in gene expression. Hum Mol Genet 8:1253-1262.

Griffiths R. 1984. The abilities of young children. London: University of London Press.

Hoffbuhr K, Devaney JM, LaFleur B, Sirianni N, Scacheri C, Giron J, Schuette J, Innis J, Marino M, Philippart M, Narayanan V, Umansky R, Kronn D, Hoffman EP, Naidu S. 2001. MeCP2 mutations in children with and without the phenotype of Rett syndrome. Neurology 56:14861495 . 
Kleefstra T, Yntema HG, Nillesen WM, Oudakker AR, Mullaart RA, Geerdink N, van Bokhoven H, de Vries BB, Sistermans EA, Hamel BC. 2004. MECP2 analysis in mentally retarded patients: Implications for routine DNA diagnostics. Eur J Hum Genet 12:24-28.

Kriaucionis S, Bird A. 2004. The major form of MeCP2 has a novel Nterminus generated by alternative splicing. Nucleic Acids Res 32:18181823.

Lam CW, Yeung WL, Ko CH, Poon PM, Tong SF, Chan KY, Lo IF, Chan LY, Hui J, Wong V, Pang CP, Lo YM, Fok TF. 2000. Spectrum of mutations in the MECP2 gene in patients with infantile autism and Rett syndrome. J Med Genet 37:e41.

Liu Q, Feng J, Buzin C, Wen C, Nozari G, Mengos A, Nguyen V, Liu J, Crawford L, Fujimura FK, Sommer SS. 1999. Detection of virtually all mutations-SSCP (DOVAM-S): A rapid method for mutation scanning with virtually $100 \%$ sensitivity. Biotechniques 26: 932, 936-938, 940942.

Lobo-Menendez F, Sossey-Alaoui K, Bell JM, Copeland-Yates SA, Plank SM, Sanford SO, Skinner C, Simensen RJ, Schroer RJ, Michaelis RC. 2003. Absence of MeCP2 mutations in patients from the South Carolina autism project. Am J Med Genet Part B 117B:97-101.

Lord C, Rutter M, Le Couteur A. 1994. Autism Diagnostic InterviewRevised: A revised version of a diagnostic interview for caregivers of individuals with possible pervasive developmental disorders. J Autism Dev Disord 24:659-685.

Lord C, Cook EH, Leventhal BL, Amaral DG. 2000. Autism spectrum disorders. Neuron 28:355-363.

Martinowich K, Hattori D, Wu H, Fouse S, He F, Hu Y, Fan G, Sun YE. 2003. DNA methylation-related chromatin remodeling in activity-dependent BDNF gene regulation. Science 302:890-893.

Mnatzakanian GN, Lohi H, Munteanu I, Alfred SE, Yamada T, MacLeod PJ, Jones JR, Scherer SW, Schanen NC, Friez MJ, Vincent JB, Minassian BA. 2004. A previously unidentified MECP2 open reading frame defines a new protein isoform relevant to Rett syndrome. Nat Genet 36:339341.

Rutter M. 2005. Aetiology of autism: Findings and questions. J Intellect Disabil Res 49:231-238.
Samaco RC, Nagarajan RP, Braunschweig D, LaSalle JM. 2004. Multiple pathways regulate MeCP2 expression in normal brain development and exhibit defects in autism-spectrum disorders. Hum Mol Genet 13:629639.

Schopler E, Reichler RJ, Renner BR. 1988. The childhood autism rating scale (CARS). Los Angeles, CA: Western Psychological Services.

Shibayama A, Cook EH, Jr., Feng J, Glanzmann C, Yan J, Craddock N, Jones IR, Goldman D, Heston LL, Sommer SS. 2004. MECP2 structura and 3'-UTR variants in schizophrenia, autism and other psychiatric diseases: A possible association with autism. Am J Med Genet Part B 128B:50-53.

Trappe R, Laccone F, Cobilanschi J, Meins M, Huppke P, Hanefeld F, Engel W. 2001. MECP2 mutations in sporadic cases of Rett syndrome are almost exclusively of paternal origin. Am J Hum Genet 68:1093-1101.

van Karnebeek CD, van Gelderen I, Nijhof GJ, Abeling NG, Vreken P, Redeker EJ, van Eeghen AM, Hoovers JM, Hennekam RC. 2002. An aetiological study of 25 mentally retarded adults with autism. J Med Genet 39:205-213.

Vincent JB, Melmer G, Bolton PF, Hodgkinson S, Holmes D, Curtis D, Gurling HM. 2005. Genetic linkage analysis of the X chromosome in autism, with emphasis on the fragile X region. Psychiatr Genet 15:8390.

Wan M, Lee SS, Zhang X, Houwink-Manville I, Song HR, Amir RE, Budden S, Naidu S, Pereira JL, Lo IF, Zoghbi HY, Schanen NC, Francke U. 1999. Rett syndrome and beyond: Recurrent spontaneous and familial MECP2 mutations at CpG hotspots. Am J Hum Genet 65:1520-1529.

Ylisaukko-Oja T, Rehnstrom K, Vanhala R, Kempas E, von Koskull H, Tengstrom C, Mustonen A, Ounap K, Lahdetie J, Jarvela I. 2005. MECP2 mutation analysis in patients with mental retardation. Am J Med Genet Part A 132A:121-124.

Yu F, Thiesen J, Stratling WH. 2000. Histone deacetylase-independent transcriptional repression by methyl-CpG-binding protein 2 . Nucleic Acids Res 28:2201-2206.

Zappella M, Meloni I, Longo I, Canitano R, Hayek G, Rosaia L, Mari F Renieri A. 2003. Study of MECP2 gene in Rett syndrome variants and autistic girls. Am J Med Genet Part B 119B:102-107. 